\title{
DRYER SEGEL BOTOL PLASTIK UNTUK PENINGKATAN KUALITAS KEMASAN BOTOL VITAMIN UNGGAS DI KECAMATAN PURWOSARI KABUPATEN PASURUAN
}

\author{
Soeparno Djiwo ${ }^{1 *}$, Gerald A. Pohan ${ }^{2}$, Djoko H. Praswanto ${ }^{3}$ \\ 1,2,3 Jurusan Teknik Mesin, Fakultas Teknologi Industri, Institut Teknologi Nasional Malang \\ *Email Korespondensi: soeparno d $@$ yahoo.com
}

\begin{abstract}
ABSTRAK
Pada sistem penjualan sebuah produk, ada beberapa faktor yang mempengaruhinya. Salah satu faktor yang mempengaruhi perhatian konsumen yaitu kemasan / packaging. Kemasan mempunyai efek yang signifikan terhadap hasil penjualan. Hal ini dikarenakan desain kemasan yang digunakan pada sebuah produk dapat menunjukkan bahwa produk tersebut benar-benar mempunyai kwalitas. Meskipun produk yang dijual tersebut belum terkenal di masyarakat, hal pertama yang dilihat untuk memastikan produk tersebut kwalitas terjamin dilihat dari desain kemasan yang digunakan. Pada jaman milenial sekarang ini, model kemasan bermacam-macam. UKM-UKM yang muncul ditengah masyarakat mulai memperbaiki kemasan untuk meningkatkan harga jual produknya. Salah satunya UKM di Kecamatan Purwosari Kabupaten Pasuruan, UKM yang bergerak dibidang vitamin unggas ini mulai mementingkan model kemasan yang digunakan. Pada UKM tersebut untuk mengemas produknya agar menarik peternak, menggunakan kemasan botol. Hal ini dikarenakan kemasan botol dapat menjaga produknya dari faktor-faktor lain yang dapat merusak kualitas produk. Untuk menjamin keaslian produk, digunakan segel plastik pada botol tersebut. Dalam proses pembuatan segel menggunakan dryer yang didesain sesuai model botol agar dapat menghasilkan segel botol yang maksimal sehingga menraik untuk dilihat oleh konsumen. Dari hasil yang didapat dengan menggunakan dryer segel botol ini, kemasan botol vitamin terlihat rapi dan menarik serta dapat meningkatkan permintaan konsumen $50 \%$ dari sebelumnya.
\end{abstract}

Kata kunci : Sistem Penjualan, Kemasan, Botol, Dryer, Segel.

\section{ABSTRACT}

In a product sales system, several factors influence it. One factor that influences customer attention is the packaging. Packaging has a significant effect on sales results. This is because the packaging design used in a product can show that the product has quality. Even though the product sold is not yet well known in the community, the first thing that is seen to ensure that the product is of guaranteed quality is seen from the packaging design used. In today's millennial era, various packaging models. UKM-UKM that appear during the community is starting to improve the packaging to increase the selling price of their products. One of them is UKM in Purwosari Subdistrict, Pasuruan Regency. The UKM engaged in poultry vitamins are starting to emphasise the packaging model used. In these UKM to package their products to attract farmers, using bottle packaging. This is because bottle packaging can keep the product from other factors that can damage the quality of the product. To guarantee the authenticity of the product, a plastic seal on the bottle is used. In the process of making seals using a dryer that is designed according to the bottle model so that it can produce a maximum bottle seal so that consumers can see it. From the results obtained by using this dryer bottle seal, vitamin bottle packaging looks neat and attractive and can increase consumer demand by 50\% from before.

Keywords: Sales System, Packaging, Bottles, Dryer, Seals.

\section{PENDAHULUAN}

Dalam sistem penjualan, terdapat beberapa faktor-faktor yang mempengaruhinya. Salah satu faktor yang mempengaruhi penjualan yaitu, kemasan. Kemasan yang digunakan untuk melindungi produk didesain secara unik dan menarik. Kemasan yang unik dapat menarik perhatian konsumen, sehingga kemasan mempunyai perubahan yang signifikan dan positif 
terhadap hasil penjualan. Desain kemasan yang unik dan kreatif dapat berpengaruh signifikan terhadap impulse buying produk (Abdalkarim \& Ra'id, 2013; Banerjee \& Sunetra, 2012). Pada jaman milenial sekarang ini, kemasan merupakan hal utama diperhatikan dalam UKM-UKM yang ada dimasyarakat. UKM melakukan perkembangan melalui perbaikan model kemasan yang digunakan untuk membuat produknya lebih banyak diminati oleh pelanggan. Salah satu contohnya UKM yang terdapat di Kecamatan Purwosari Kabupaten Pasuruan, UKM ini telah berdiri sejak tahun 2011. UKM yang bergerak dibidang vitamin unggas ini produknya terjual stagnan dan bahkan pernah mengalami penurunan. Hal utama sebelumnya yang dilakukan pemilik UKM pada saat mengalami penurunan penjualan memperbaiki kwalitas produk saja. Tetapi hasil yang didapat dari penyelesaian masalah tersebut tidak dapat meningkatkan nilai jual produknya. Pada tahun 2017 UKM mencoba memperbaiki model kemasan yang digunakan. Sebelumnya kemasan yang digunakan dari karung diganti menjadi botol. Dengan perubahan seperti ini terjadi peningkatan permintaan pasar. Dengan banyaknya produk yang terjual terdapat permasalahan yang muncul yaitu produknya ditiru atau dipalsu oleh orang lain. Sehingga UKM melakukan perbaikan dengan menjaga keaslian produk menggunakan segel plastik.

Untuk menjaga keaslian produk pada kemasan hanya menggunakan segel. Segel pada kemasan bermacam - macam model. Yang terdapat dipasaran, model segel pada kemasan botol, yaitu segel pada tutup botol, segel plastik hanya dibagian atas botol dan segel plastik keseluruhan botol. Segel merupakan salah satu pengaman pada kemasan yang dapat menunjukkan keaslian produk dan dengan adanya segel pada kemasan, konsumen dapat lebih tertarik karena keaslian produk terjamin (Christy \& Ellyawati, 2015; Dhameria, 2014; Hutagalung, 2010; Kotler \& Amstrong, 2012). Pada UKM di kecamatan Purwosari Kabupaten Pasuruan, dalam kemasannya menggunakan botol yang disegel secara kesuluruhan menggunakan plastik. Selama ini pembuatan segel menggunakan hair dryer, sehingga hasilnya tidak bisa rapi. Hal ini dikarenakan panas yang diberikan untuk plastik segel tidak merata sehingga banyak lempitan-lempitan plastik yang terlihat dibotol. Dengan keadaan seperti ini akan mempengaruhi tampilan dan daya tarik produk tersebut (Kotler \& Keller, 2012; Natadjaja, et al., 2017; Santoso, 2013; Sularso \& Suga, 1997; Susetyarsi, 2012).

Agar mendapatkan tampilan yang rapi dan menarik dalam kemasan perlu dilakukan perubahan metode pembuatan segel. Oleh karena itu dibutuhkan dryer khusus agar dalam penyegelan terlihat rapi. Untuk itu dalam penyegelan sekarang ini menggunakan dryer yang didesain sesuai botol. Tujuan menggunakan desain ini agar segel dapat terpasang rapi dan sesuai dengan bentuk botolnya. Dalam dryer ini, terdapat pengaturan temperatur, kecepatan angin dan kecepatan putar botol. Sehingga dengan dilengkapi pengontrolan seperti ini nantinya dalam pembuatan segel dapat rapi dan tidak ada lempitan plastik yang menggangu tampilan kemasan.

\section{METODE}

Metode yang digunakan yaitu metode pendekatan kepada mitra untuk meningkatkan kwalitas produk dari aspek kemasan yang bersegel. Selain itu juga menerapkan sistem on the job training (OJT) pada pengelola mitra mulai dari cara penggunaan dryer, perawatan dan perbaikan dryer. Dalam pembuatan segel menggunakan dryer yang didesain sesuai dengan botol, dilengkapi dengan alat kontrol temperatur, kecepatan udara dan kecepatan putaran botol.

Spesifikasi dryer :

- Elemen pemanas (Heater) 250 watt

- Blower debit udara $420 \mathrm{~L} / \mathrm{min}$

- Rangka Alumunium

- Voltase 220 volt 
Cara kerja dryer :

- Setting temperatur sampai suhu $90^{\circ} \mathrm{C}$, kemudian diamkan sampai stabil

- Hidupkan fan / blower dan setting dimmer pada posisi level 4

- Pasang plastik segel ke botol dan letakkan botol ke penompang rangka dryer

- Hidupkan dinamo agar botol berputar.

- Setelah plastik segel menempel merata matikan dinamo putaran botol dan blower.

Dryer segel botol ini mempunyai desain yang efisien dan ringan seperti pada Gambar

1. Tujuan didesain seperti ini agar dryer dapat dipindah-pindah dan tidak membutuhkan ruang yang luas. Dengan ditambahkan dinamo di alas botol agar botol berputar sehingga plastik segel dapat menempel ke botol dengan merata. Dryer segel dilengkapi dengan dimmer agar debit udara blower dapat diatur sesuai dengan kebutuhan, karena ketebalan plastik segel mempengaruhi debit udara yang dibutuhkan. Serta dilengkapi kontrol temperatur agar dapat menyeseuaikan ketebalan plastik segel yang digunakan. Dryer segel ini dirancang agar dapat memberikan keamanan produk dengan melihat aspek kerapian dan dapat menarik minat pembeli.
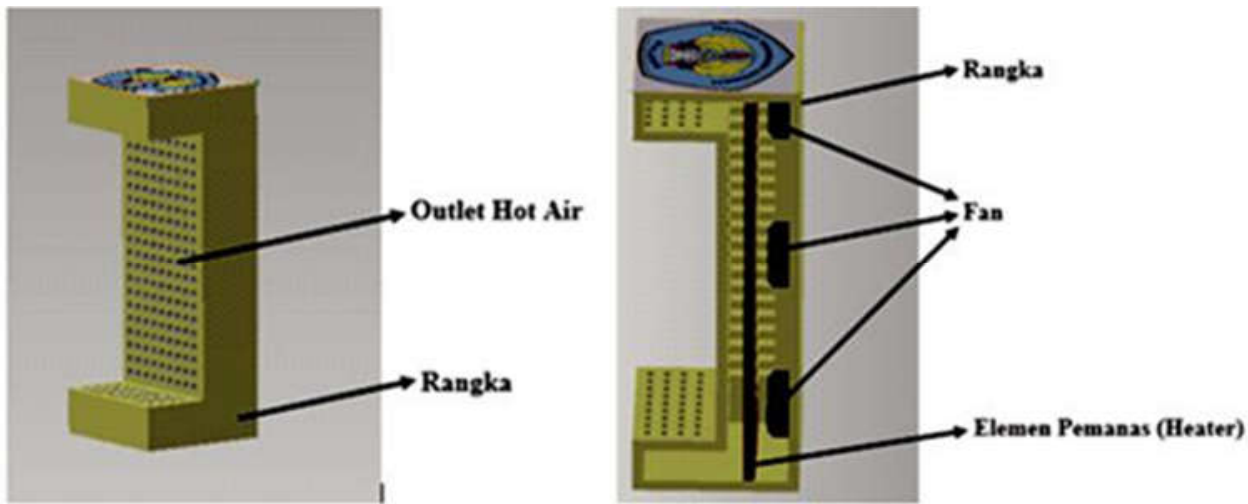

Gambar 1. Desain dryer segel botol

\section{HASIL DAN PEMBAHASAN}

Hasil pengujian yang dilakukan dengan mitra, untuk mencari bahan yang digunakan, temperatur, debit udara blower dan kecepatan putaran dinamo. Bahan yang digunakan sebagai segel menggunakan plastik PET dengan ketebalan $1 \mathrm{~mm}$. Temperatur yang digunakan $90^{\circ} \mathrm{C}-100^{\circ} \mathrm{C}$ dan debit udara blower yang diatur menggunakan dimmer dengan rata-rata kecepatan udara $450 \mathrm{~L} / \mathrm{min}$. Sedangkan putaran dinamo yang digunakan untuk memutar botol menggunakan dimer kecepatan yaitu $3 \mathrm{~m} / \mathrm{s}$. Dari parameter-parameter tersebut ditetapkan dari hasil uji coba yang telah dilakukan diambil parameter yang paling terbaik diukur dari hasil kwalitas segel yang didapatkan.

Dari hasil uji coba seperti pada Tabel 1, setiap penggunaan bahan plastik segel yang berbeda mempengaruhi parameter-parameter lainnya, seperti temperatur, debit udara blower dan kecepatan putaran botol. Tetapi dengan meningkatnya temperatur diatas $90^{\circ} \mathrm{C}$, plastik akan rusak apabila menggunakan plastik dengan ketebalan $1 \mathrm{~mm}$. Ditinjau dari debit udara blower semakin tinggi debit maka kwalitas segel semakin rapi. Sehingga dari hasil uji coba diambil yang terbaik kemudian didapatkan paramater yang sesuai seperti yang sudah dijelaskan diatas.

Dengan memperhitungkan biaya kebutuhan listrik menggunakan persamaan :

Biaya Listrik $=$ Total Kwh $\mathrm{x}$ waktu $\mathrm{x} 1355$

1355 didapatkan dari harga per 1 kwh pada listrik yang menggunakan daya 1300 VA. Dari hasil perhitungan didapatkan biaya kebutuhan listrik seperti Tabel 2. 
Tabel 1. Hasil Percobaan

\begin{tabular}{|c|c|c|c|c|}
\hline $\begin{array}{c}\text { Temperatur } \\
\left({ }^{\circ} \mathrm{C}\right)\end{array}$ & $\begin{array}{l}\text { Debit Udara } \\
\text { (L/min) }\end{array}$ & $\begin{array}{c}\text { Kecepatan } \\
\text { Motor }(\mathrm{m} / \mathrm{s})\end{array}$ & Waktu (s) & Hasil \\
\hline \multirow{9}{*}{ (c) } & \multirow{3}{*}{250} & 1 & 300 & \multirow{9}{*}{$\begin{array}{l}\text { Segel plastik } \\
\text { kurang rapat }\end{array}$} \\
\hline & & 2 & 280 & \\
\hline & & 3 & 250 & \\
\hline & \multirow{3}{*}{350} & 1 & 285 & \\
\hline & & 2 & 270 & \\
\hline & & 3 & 245 & \\
\hline & \multirow{3}{*}{450} & 1 & 275 & \\
\hline & & 2 & 265 & \\
\hline & & 3 & 240 & \\
\hline \multirow{9}{*}{90} & \multirow{3}{*}{250} & 1 & 290 & \multirow{9}{*}{$\begin{array}{l}\text { Segel plastik } \\
\text { rapat }\end{array}$} \\
\hline & & 2 & 275 & \\
\hline & & 3 & 245 & \\
\hline & \multirow{3}{*}{350} & 1 & 280 & \\
\hline & & 2 & 260 & \\
\hline & & 3 & 240 & \\
\hline & \multirow{3}{*}{450} & 1 & 270 & \\
\hline & & 2 & 255 & \\
\hline & & 3 & 235 & \\
\hline \multirow{9}{*}{100} & \multirow{3}{*}{250} & 1 & 270 & \multirow{3}{*}{$\begin{array}{l}\text { Segel plastik } \\
\text { rapat }\end{array}$} \\
\hline & & 2 & 255 & \\
\hline & & 3 & 235 & \\
\hline & \multirow{3}{*}{350} & 1 & 270 & \multirow{6}{*}{$\begin{array}{l}\text { Segel plastik } \\
\text { rusak }\end{array}$} \\
\hline & & 2 & 245 & \\
\hline & & 3 & 230 & \\
\hline & \multirow[t]{3}{*}{450} & 1 & 250 & \\
\hline & & 2 & 235 & \\
\hline & & 3 & 205 & \\
\hline
\end{tabular}

Dengan melihat biaya produksi dan hasil kwalitas segel plastik yang dapat digunakan temperatur $90-100{ }^{\circ} \mathrm{C}$. Tetapi disisi lain biaya listrik yang digunakan juga perlu diperhitungkan. Melihat hasil perhitungan biaya listrik yang paling rendah pada temperatur $90^{\circ} \mathrm{C}$ dengan debit udara $450 \mathrm{~L} / \mathrm{min}$ dan kecepatan motor $3 \mathrm{~m} / \mathrm{s}$ membutuhkan biaya per segel botol sebesar Rp. 28,-. Jika dibandingkan dengan penyegelan ke jasa segel ditempat lain, penyegelan dilakukan sendiri lebih murah. Penyegelan ditempat lain membutuhkan biaya Rp. 5000,- per botol sedangkan jika dilakukan penyegelan sendiri menghabiskan biaya sekitar Rp. 2000,- jadi lebih menghemat Rp. 3000,-.

Perbaikan dalam kemasan dengan memberikan segel menjadi keamanan produk menjadi salah satu faktor yang dapat mempengaruhi ketertarikan konsumen dalam memilih produk. Dengan adanya dryer ini, permintaan konsumen yang rata-rata dari peternak langsung meningkat. Hal ini dibuktikan setelah adanya dryer ini permintaan dari peternak yang sebelumnya 1 bulan mencapai 1,5 ton menjadi 3,5 ton per bulan. Dengan peningkatan penjualan seperti ini dapat meningkatkan keberhasilan mitra dalam menyelesaikan permasalahan yang dihadapinya.

Selain menemukan parameter yang digunakan, juga memberikan pelatihan dan perawatan pada dryer segel. Sehingga apabila terjadi kerusakan pada dryer, pengelola mitra bisa memperbaikinya. Dengan bertambahnya ketrampilan pada pengelola dapat digunakan untuk mengembangkan usahanya dengan membuka jasa pembuatan segel pada kemasan ukm-ukm lainnya yang membutuhkan kemasan produk. Sehingga usaha mitra tidak hanya 
di bidang produksi vitamin unggas saja, tetapi bisa dikembangkan menjadi usaha produksi kemasan skala usaha menengah kebawah di masyarakat.

Tabel 2. Hasil Perhitungan Biaya

\begin{tabular}{|c|c|c|c|c|}
\hline $\begin{array}{c}\text { Temperatur } \\
\left({ }^{\circ} \mathrm{C}\right)\end{array}$ & $\begin{array}{l}\text { Debit Udara } \\
(\mathrm{L} / \mathrm{min})\end{array}$ & $\begin{array}{c}\text { Kecepatan } \\
\text { Motor }(\mathrm{m} / \mathrm{s})\end{array}$ & Waktu (s) & Biaya (Rp) \\
\hline \multirow{9}{*}{80} & \multirow{3}{*}{250} & 1 & 300 & \multirow{9}{*}{$\begin{array}{l}300 \\
280 \\
250 \\
285 \\
270 \\
245 \\
275 \\
265 \\
240\end{array}$} \\
\hline & & 2 & 280 & \\
\hline & & 3 & 250 & \\
\hline & \multirow{3}{*}{350} & 1 & 285 & \\
\hline & & 2 & 270 & \\
\hline & & 3 & 245 & \\
\hline & \multirow{3}{*}{450} & 1 & 275 & \\
\hline & & 2 & 265 & \\
\hline & & 3 & 240 & \\
\hline \multirow{9}{*}{90} & \multirow{3}{*}{250} & 1 & 290 & \multirow{9}{*}{$\begin{array}{l}300 \\
280 \\
250 \\
285 \\
270 \\
245 \\
275 \\
265 \\
240\end{array}$} \\
\hline & & 2 & 275 & \\
\hline & & 3 & 245 & \\
\hline & \multirow{3}{*}{350} & 1 & 280 & \\
\hline & & 2 & 260 & \\
\hline & & 3 & 240 & \\
\hline & \multirow{3}{*}{450} & 1 & 270 & \\
\hline & & 2 & 255 & \\
\hline & & 3 & 235 & \\
\hline \multirow{9}{*}{100} & \multirow{3}{*}{250} & 1 & 270 & \multirow{4}{*}{$\begin{array}{l}270 \\
245 \\
230 \\
270\end{array}$} \\
\hline & & 2 & 255 & \\
\hline & & 3 & 235 & \\
\hline & \multirow{3}{*}{350} & 1 & 270 & \\
\hline & & 2 & 245 & 245 \\
\hline & & 3 & 230 & 230 \\
\hline & \multirow[t]{3}{*}{450} & 1 & 250 & 250 \\
\hline & & 2 & 235 & 235 \\
\hline & & 3 & 205 & 205 \\
\hline
\end{tabular}

\section{DAMPAK DAN MANFAAT}

Dampak maupun manfaat yang diterima oleh mitra UKM di Kecamatan Purwosari Kabupaten Pasuruan yaitu, dengan adanya dryer segel dapat membantu membuat kemasan lebih menarik dan dijamin keaslian produk sehingga dapat meningkatkan permintaan masyarakat. Hal ini dibuktikan sebelum dan setelah adanya dryer segel ini mengalami perubahan. Setelah adanya dryer segel ini penjualan bisa mencapai 3,5 ton per bulan sehingga mengalami peningkiatan kurang lebih 50\% dari sebelumnya. Selain bermanfaat pada mitra, peternak juga bisa merasakan. Hal ini dikarenakan dengan adanya kemasan yang bersegel dapat menjamin kwalitas produk dan dapat menjaga produk dari kerusakan akibat faktor lain yang dapat merusak vitamin unggas.

\section{KESIMPULAN}

Segel dalam kemasan merupakan hal yang utama perlu diperhatikan dalam penjualan produk. Dengan segel kemasan yang rapi dan menarik perhatian costumer dapat meningkatkan jumlah pembeli karena dengan kemasan yang rapi dan menarik dapat menunjukkan kwalitas produk. Adanya dryer segel untuk kemasan botol vitamin unggas ini 
dapat meningkatkan penjualan sebesar $50 \%$ dari sebelumnya yaitu dari permintaan 1,5 ton per bulan menjadi 3,5 ton per bulan.

\section{UCAPAN TERIMA KASIH}

Ucapan terima kasih disampaikan kepada Lembaga Penelitian dan Pengabdian Masyarakat Institut Teknologi Nasional Malang yang telah berkontribusi memberikan bantuan berupa dana pengabdian masyarakat untuk kelancaran kegiatan pengabdian masyarakat.

\section{REFERENSI}

Abdalkarim, G. M. dan Ra'id, S. (2013). 'The Role of Packaging in Consumer's Perception of Product Quality at the Point of Purchase'.

Banerjee, S. dan Sunetra, S. (2012) 'Impulse Buying Behavior in Retail Stores - Triggering the Sense', Asia Pacific Journal of Marketing and Management Review, 1(2), ISSN 2319-2836.

Christy P. dan Ellyawati, J. (2015) 'Pengaruh Desain Kemasan (Packaging) Pada Impulsive Buying', Jurnal UAJY.

Dhameria, V. (2014) 'Analisis Pengaruh Keunikan Desain Kemasan Produk, Kondusivitas Store Environment, Kualitas Display Produk Terhadap Keputusan Pembelian Impulsif', Jurnal Sains Pemasaran Indonesia. XIII(1).

Hutagalung, F. D. (2010) 'Perbaikan Fasilitas Kerja Pada Proses Penjalinan Untuk Meningkatkan Produktivitas di UD Pusaka Bakti', Dari http://www. repository.usu.ac.id

Kotler, P. dan Amstrong, G. (2012) 'Principles Of Marketing', Edisi 14, Global Edition. Pearson Prentice Hall.

Kotler, P. dan Keller, K. L. (2012) 'Marketing Management', Edisi 14, Global Edition. Pearson Prentice Hall.

Natadjaja, L., Cahyono, Y. B. dan Yuwono, E. C. (2017) 'Kondisi Desain Kemasan Produk Makanan Ringan Dan Minuman Instant Pada Industri Kecil Skala Rumah Tangga (Micro Industry) Di Kabupaten Kediri', Jurnal Manajemen Bisnis UK. 12(1).

Santoso, K. (2013) 'Pengaruh Kualitas Produk, Harga dan Promosi Terhadap Keputusan Pembelian Permen Tolak Angin di Semarang', Universitas Diponegoro Journal of Social and Politic. Hal 1-10. http://ejournal-s1/undip.ac.id/index. php/ diakses 30 September 2018.

Sularso dan Suga, K (1997) 'Dasar Perencanaan Dan Pemilihan Elemen Mesin', Jakarta, Pradnya Paramita.

Susetyarsi, T. (2012) 'Kemasan Produk Ditinjau Dari Bahan Kemasan, Bentuk Kemasan Dan Pelabelan Pada Kemasan Pengaruhnya Terhadap Keputusan Pembelian Pada Produk Minuman Mizone Di Kota Semarang', Jurnal STIE Semarang. 4(3). 19-28. 